\title{
ARTICULAÇÃO DA REDE DE MULHERES NEGRAS NA DIÁSPORA AFRICANA: TRADIÇÃO VIVA, CONTRADITÓRIA, EM CONSTANTE REINVENÇÃO
}

\author{
Maísa Maria Vale ${ }^{1}$ \\ Lina Maria Brandão de $\operatorname{Aras}^{2}$
}

Resumo: Este trabalho busca refletir sobre o processo de organização e mobilização da Rede de Mulheres Negras em torno da luta antirracista e antissexista, que as coloca em condições por demais desfavoráveis na estrutura social-política-econômica do Brasil. Destacamos as estratégias e metodologias adotadas para fazer acontecer a I Marcha das Mulheres Negras à Brasília, inspirada em valores ancestrais, trazidos de uma outra bacia semântica, outro modelo civilizatório. Esta sabedoria milenar tem sido o mote desses mo$d u s$ de ser e estar neste não-lugar, contrário à cristalização de lugares sociais para as pessoas negras nesta e pela garantia de uma vida sem violência.

Palavras-chave: Mulheres Negras, Identidades, Diáspora Africana, Feminismo Negro.

\section{NETWORK OF WOMEN IN BLACK JOINT AFRICAN DIASPORA: LIVING HERITAGE, CONTRADICTORY, IN CONSTANT REINVENTION}

\begin{abstract}
This paper seeks to reflect on the process of organization and mobilization of the Black Women's Network about the fight against racism and anti-sexist, that puts them in conditions too unfavorable social-political-economic structure of Brazil. In addition, it highlights the strategies and methodologies adopted to make it happen I March of Black Women in Brasilia, inspired by ancestral values, religion and culture, the result of another semantic basin, another civilization model. This ancient wisdom has been the motto of these modus of being and non - being in this place, contrary to the crystallization of social places for black people in this and ensuring a life without violence.

Keywords: Black Women, Identities, African Diaspora, Black Feminism.
\end{abstract}

\section{Introdução}

Este trabalho propõe uma reflexão sobre as estratégias adotadas pela Rede de mulheres negras no processo de mobilização de pessoas, especialmente para I Marcha das Mulheres

1 Doutoranda e Mestre em Estudos Interdisciplinares sobre Mulheres, Gênero e Feminismo NEIM/UFBA. Atualmente é Coordenadora do ODARA — Instituto da Mulher Negra e colaboradora do ICEAFRO: Educação para a Igualdade Racial e de Gênero. Pesquisadora da UNILAB — Grupo de Estudos e Pesquisas sobre Políticas Públicas, Igualdade Racial, Gênero, Desenvolvimento e Territorialidade. Dentre as publicações, a mais recente é "Mulheres Negras na Política: Trajetória social e política de mulheres negras candidatas às eleições municipais de Salvador (2008-2012)", 2014. E-mail: maisavale@hotmail.com.

2 Professora Dra. Titular do Departamento de História, da Universidade Federal da Bahia - UFBA e do Programa de Pós-Graduação em Estudos Interdisciplinares sobre Mulheres, Gênero e Feminismo - UFBA. Doutora em História Social pela Universidade de São Paulo - USP e pós-doutorado na Universidade Federal de Pernambuco - UFPE. Coordenadora do Projeto de Pesquisa Narrativa sobre Mulheres nas Américas, atuando principalmente nos seguintes temas: rebeldias, região, literatura e gênero. E-mail: maisavale@hotmail.com. 
Negras à Brasília, em novembro de 2015. Adotamos como ponto de partida o seguinte questionamento: qual o contexto em que mulheres negras se lançam numa articulação nacional para exigir o fim do racismo, da violência e propor um novo pacto civilizatório para o Estado e sociedade no Brasil? Ao analisar o processo de organização da Rede em torno da luta antirracista e antissexista exista no Brasil, outra questão também se impõe: quais as condições históricas particulares - econômicas e sociais - que reúne em Brasília mais de sessenta mil mulheres negras de todo país para propor ao Estado brasileiro um novo pacto civilizatório, fundado numa outra linha semântica para a vida presente?

Refletir sobre tais perguntas é, sem sobra de dúvida, considerar que essas questões estão vinculadas a situações políticas conjunturais no sentido mais amplo do termo. São reflexos de problemas estruturais que não surgiram hoje, mas resultaram de inúmeros processos de expropriação e negação, que se estendem desde os tempos coloniais, passando pelo tráfico transatlântico de africanos/as escravizados/as, aportando-se no século XXI, quando registramos os mais diversos tipos de violências contra as mulheres negras.

A deliberação destas mulheres de marchar está vinculada com a própria dinâmica da sua condição diaspórica, enquanto lugares de pertencimento, mas, sobretudo, enquanto espaço de luta e resistência. Esta constatação advém do fato de que o movimento de mulheres negras, desde as suas primeiras manifestações, tem se fundamentado na tradição e sabedoria africana, reinventadas e reinterpretadas cotidianamente neste ambiente de diáspora. Estes conhecimentos, transmitidos quase que na sua totalidade oralmente pelas ancestrais, têm sido fonte de inspiração para as práticas e ação política de resistência em prol de uma existência sem racismo e sexismo.

As mulheres negras chegaram aos dias atuais promovendo tensões diversas na sociedade, questionando as condição social e histórica a que foram impostas, incompatíveis com termos como cidadania, democracia, modernidade e, até mesmo, mulher, em virtude do seu envolvimento com ideias inseparáveis de exploração e subalternização. Daí o choque entre dois modelos civilizatórios, fundamentalmente distintos e antagônicos que se contrapõem em termos de valores, crenças, tradições, princípios e visão de mundo.

Neste momento em que começamos a admitir que a sociedade ocidental alcançouum esgotamento que parece conduzir a uma situação de crise estrutural, mas também de limitação 
do alcance da perspectiva pós-moderna, a"bacia semântica"3 dominante passa a ser colocada sob suspeição. Em termos gerais outras reconfigurações para a vida presente, especialmente nestes momentos de crise, tende a ressurgir de outras áreas como instrumentos mais eficazes, vivenciados por experiências coletivas das sociedades tradicionais até então marginalizadas, tendem a emergir como alternativa para livrar o mundo do abismo em que se colocou.

A complexa tarefa de contextualizar a mola propulsora desta decisão das mulheres negras de se reinventar na luta do movimento negro e de marchar à Brasília, foram apropriados a noção de identidades - construídas especialmente sob a ideia de pertencimento, principalmente racial e de gênero, afirmadas pela sua plasticidade e com um forte viés de cunho político. Busca apoio, ainda, no pensamento sobre diáspora negra, proposto por Robin Cohen (2008) que, influenciado por leituras pós-modernas, teve decomposto alguns de seus elementos fundamentais, a exemplo de "terra natal" e "comunidade étnico-religiosa" (2008, p. 520). Face às complexidades que delimitavam tais ideias, termos como culturas e identidades tiveram que ser radicalmente reorganizadas, reconceitualizadas, desterritorializadas e afirmadas como flexível, situacional,enquanto experiências políticas diversas que vai de encontro à ideia de uma "unanimidade racial" (GILROY, 2001, p. 256) ${ }^{4}$ e de gênero.

A decisão por organizar a Rede de Mulheres Negras partiu da necessidade da criação de uma rede de informação e solidariedade capaz de manter as mulheres de todo país mobilizadas. Para tanto conceitos como identidade étnica e diáspora negra foram apropriados dando sentido a outros termos como ancestralidade, legado, tradição, memória, frequentes na linguagem e cotidiano destas mulheres, porém sem a apropriação do cunho político necessário a sua utilização.

Para abordar este tema foi desenvolvido o argumento em três passos distribuídos da seguinte forma: Primeiro, descrevendo brevemente o que se entende por esta identidade "Mulheres Negras", ressaltando-a como resultado de experiências históricas coletivas pautadas em um saber ancestral, que desde o início tem estimulado um ponto de vista

3 Conjunto de ideias, significados, expressões que, segundo a proposta por Gilbert Durand e inspirada no inconsciente coletivo da teoria junguiana, orientam e sustentam em profundidade a vida, ou seja, nossa maneira de ser. Confirmam o modo de ser em dada sociedade.

4 Ver também: HALL, Stuart. Da diáspora: identidades e mediações culturais. Belo Horizonte/Brasília: UFMG/UNESCO, 2003. COHEN, Robin. Sólidas, Dúcteis e Líquidas: noções em mutação de "lar" e "terra natal” nos estudos da diáspora. Caderno CRH, Salvador, v. 21, n. 54, p. 519-532, set./dez. 2008. 
específico, que, por sua vez, caracteriza as experiências políticas deste sujeito e de suas organizações. O segundo ponto é apropriado a partir da perspectiva analítica fornecida pelo conceito de diáspora africana. As identidades — raça e gênero — são concebidas como formas geo-políticas e geo-culturais de vida resultantes da interação entre sistemas comunicativos e contextos (Idem, p. 24). Por meio dos conceitos de identidade étnica e diáspora africana serão apresentadas algumas passagens estratégicas do movimento de Mulheres Negras para construção da I Marcha em 2015, tomando como ponto de partida as metodologias e discursos adotados para estruturar e dar forma a Rede de Mulheres Negras.

\section{Mulheres negras: quantas anônimas guerreiras brasileiras}

Até a década de setenta do século XX, o rumo adotado pela historiografia brasileira não priorizou os feitos de sujeitos considerados como subalternos. Da mesma forma que o itinerário percorrido pelas mulheres negras, suas formas de inserção, participação, mediações sociais, improvisos, até muito recentemente não haviam sido contemplados. Desse modo, ficaram de fora da história o movimento feito pelas suas ancestrais que data do desembarque da primeira traficada para o ocidente, insurgindo contra os representantes do sistema escravista, dentre outros fatos que ajudariam a compreensão dessa forma de ser, estar, se organizar para não sucumbir nas sociedades em que estão inseridas.

A década de 80 do século passado, apenas para exemplificar, se constituiu em um marco na ressignificação do lugar dos sujeitos nos processos políticos. Com a intensificação da participação popular expressa através de ações coletivas articuladas a partir de suas identidades e agendas - mulheres, negros, gays, trabalhadores, favelados e tantas outras formas de organização de "sujeitos" — até então considerados "subalternos" (SPIVAK, 2003)e silenciados por perspectivas modernizantes, passaram a ser vistos reivindicando direitos, questionando lugares e papéis sociais.

Joselina da Silva (2014) em seu artigo intitulado "I Encontro Nacional de Mulheres Negras: o pensamento das feministas negras na década de 1980" alerta sobre o risco de se tomar a organização das mulheres negras como algo que emerge com os chamados "novos movimentos" na década de 80, pois, antes disso, da década de 70 "já éramos mulheres e negras, do ponto de vista argumentativo e da construção identitária", afirma Silva (2014, p. 36).Estas desconstruções e questionamentos têm sido bastante úteis para os sujeitos tidos como subal- 
ternos na medida em que tem vislumbrado a possiblidade de um fazer científico mais rico, coerente e plural, onde o sujeito cognoscente não é tratado apenas como objeto passivo para um pesquisador que, supostamente, detém a primazia do saber epistêmico.

Destaque-se os feitos de algumas mulheres na luta por uma vida sem racismo e sem sexismo, por reconhecer a dívida histórica que sociedade brasileira tem para com estas atrizes da vida cotidiana. Reconhecendo, por assim dizer, que a história das mulheres negras no Brasil ainda está por ser contada, considerada como um compromisso que as mulheres negras, estejam na academia ou fora desta, têm se proposto a fazer. Essa ação deve partir do ponto mais longínquo que se possa imaginar, de tal modo que tenhamos uma historiografia condizente com a pluralidade constitutiva do chamado povo brasileiro.

Pesquisas recentes, realizadas sobre a ação política de afrodescendentes, individual e coletivamente, apontam para certos traços característicos da mulher negra, formas de participação, improvisos, mediações, com vistas à sobrevivência e existência dos povos descendentes de africanos dentro e fora desse continente. Defendendo que nas sociedades clivadas pelo racismo e patriarcado, dentre estas se inclui a brasileira, as relações sociais têm sido pautadas em hierarquizações fundadas em estereótipos negativos direcionados a esse corpo biológico, dando significações e sentido às inúmeras formas e posições sociais que nos deparamos cotidianamente.

Neste sentido, resulta evidente que conceitos como "raça" e "gênero", enquanto categorias de análise social permanecem como instrumentos para explicar a prevalência das marcas da diferença e reprodutora de desigualdades e injustiças em diversas esferas da sociedade brasileira. Diante de tal realidade, poderia especular que estudos envolvendo relações raciais, gênero, identidade e cultura negra requerem, necessariamente, uma maior conexão e diálogo com o campo interdisciplinar.

O conceito de diáspora africana é introduzido neste trabalho para contribuir para a discussão de fato quem é este sujeito? A partir de suas trajetórias, muitos/as pesquisadores/as deram-se conta de que a maioria de seus feitos ainda não tinha sido registrada, como ainda não às têm. As experiências históricas, os valores civilizatórios dos afro-brasileiros permanecem resguardados ainda hoje na memória social. É negada a parcela significativa da população o direito de acesso àquilo que os constitui como sujeito produtor de saberes. Um conjunto de saberes e ensinamentos vernacular que se contrapõe a memória do Eu hegemônico, opres- 
sor. Uma memória ancestral constituída por tradições e valores que os mantiveram vivos durante a vida em diáspora, de afirmação e de resistência a escravidão e a opressão.

Em seguida, é importante compreender as formas das mulheres negras de ser e estar no mundo, que tem a ver com a força do conceito de identidade para afirmação do pertencimento étnico-racial e de gênero. Reforça o uso desse conceito, pois diversas vezes o conceito de identidade vem sendo acionado para que se dê a tomada de consciência daquilo e de quem as oprime. Importante, diga-se de passagem, para forjar estratégias de resistência e enfrentamento aquilo que as coloca em condições por demais desfavoráveis na estrutura social em questão.

Além disso, tencionar aquilo que não está explícito: que a "mulher negra" não existe. Como as demais identidades, trata-se de uma construção social resultante de relações fundadas em sociedades clivadas pelo racismo e sexismo interseccionados. Neste sentido é acionada para dar sentido e justificar formas sociais de relações desiguais estruturadas para que possamos compreender as hierarquizações e formas injustas com que se distribuem os privilégios e espaços na sociedade.

O aspecto é que este sujeito é visto sob a ótica da ideia de que a diáspora africana resulta de experiências específicas forjadas a partir de um legado ancestral de tradição, que dão sentido às suas demais identidades e vão influenciar a condução dos mais variados processos organizativos e lutas contemporâneas. Finalmente, que as histórias dessas mulheres, são reconstruídas e transmitidas, quase sempre a partir de narrativas orais.

Desde que foram trazidas do continente africano para trabalhar no ocidente, na condição de mão de obra escrava, as condições atribuídas às pessoas negras sempre foram as mais adversas e desumanas. Foi neste cenário de exploração que as mulheres negras chegaram ao ocidente, assumindo responsabilidade pelo sustento de famílias negras e, principalmente, a preservação de um legado ancestral que lhe diferenciava enquanto membro do outro modelo civilizatório. Este foi se definindo em parte pela instituição da escravidão — parte intrínseca da civilização ocidental e da modernidade - mas, sobretudo, pelas culturas vernacular africana, resultado da tradição e situação pós-colonial vivenciada na diáspora negra (GILROY, 2001, p. 98).

O protagonismo deste sujeito vem de longe, desde a África, se estabelecendo no Brasil sob diversos formatos. Admitido que nada fica de fora, toda sua atuação assume uma 
conotação política mais ampla, compreendendo essa participação desde os acontecimentos que se situam antes da sua chegada ao Brasil.

Historicamente, essas experiências têm moldado as perspectivas das mulheres negras a tal ponto que seus saberes, seus feitos enquanto trabalhadora doméstica, religiosa, marisqueiras, professoras, são articulados e explorados de tal modo que o que sobressai como evidente propósito é "um ideal de vida onde o que prevalece é o viver bem juntos", para a "melhora das condições sociais de todos", buscados de diversas formas, segundo os contextos (LATOUCHE, 2004, p.195). Somos muitas, por isso podemos mais.

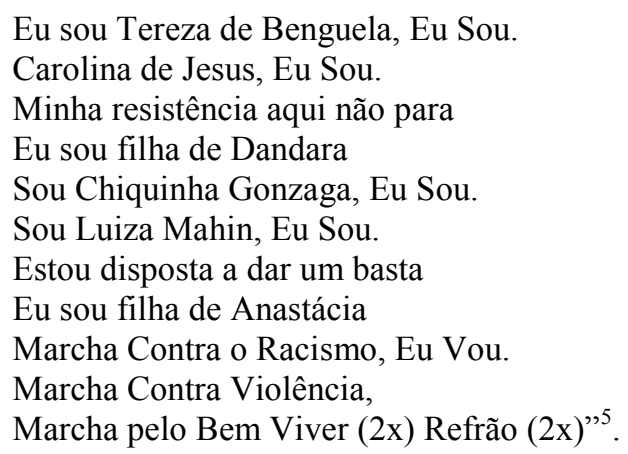

Assim estas revisões historiográficas tem servidode inspiração para tantas outras mulheres que tem tentado fazer emergir as experiências de lutas históricas e contemporâneas, de quem de fato fizeram e fazem um importante papel na história do Brasil e que ora é utilizado para reforçar a imagem que tentamos transmitir acerca do que é ser uma "Mulher Negra".

A chamada para a Marcha de Mulheres Negras à Brasília também exterioriza esse novo discurso que aponta o intercruzamento sexual e racial, como responsáveis pela perpetuação de desigualdades sociais e econômicas. Evidenciam, sobretudo, a concepção que elas têm da africanidades que carregam, homenageando às ancestrais que lutaram para a superação das desigualdades e vulnerabilidade que submetem a mulher negra nos dias atuais. É por elas que se marcha, diz o manifesto de mobilização para a Marcha:

nós mulheres negras (pretas + pardas) somos cerca de 49 milhões espalhadas por todo o Brasil; - o racismo, o machismo, a pobreza, com a desigualdade social e econômica, tem prejudicado nossa vida, rebaixando a nossa auto-estima coletiva e nossa própria sobrevivência; - o fortalecimento da identidade negra tem sido prejudicado ao longo dos séculos pela construção negativa da imagem da pessoa negra, especi-

5 Tags: Comulher - Marcha das Mulheres Negras 2015 - Mulher Negra. http://www.geledes.org.br/roda-deconversa-para-a-marcha-de-mulheres-negras. Acessado em 15 ABR. 2015. 
almente da mulher negra, desde a estética (cabelo, corpo, etc.) até ao papel social desenvolvido pelas mulheres negras; - as mulheres negras continuam recebendo os menores salários e são as que mais têm dificuldade para entrar no mundo do trabalho; - a construção do papel social das mulheres negras é sempre pensada na perspectiva da dependência, da inferioridade e da subalternização, dificultando que nós possamos assumir espaços de poder, de gerência e de decisão, quer seja no mercado de trabalho, quer seja no campo da representação política e social; - as mulheres negras sustentam o grupo familiar desempenhando tarefas informais, que as levam a trabalhar em duplas e triplas jornadas de trabalho; - ainda não temos os nossos direitos humanos (direitos civis, políticos, econômicos, sociais, culturais e ambientais) plenamente respeitados. ${ }^{6}$

De acordo com Patrícia Hill Collins (2012) a conexão que se estabelece entre o que uma pessoa faz e o que pensa, estimularam a formação de uma consciência diferenciada, que caracteriza as experiências e ideias das mulheres negras como grupo (2012, p. 104), como ocorre, na maioria das vezes, suas relações sociais - vida, educação, trabalho - atreladas à experiência com o racismo, geraram elementos que lhes propiciaram a formação de um ponto de vista em comum característico de estar em um não-lugar, de estar simultaneamente "dentro e fora" do modelo civilizatório desenhado pelo ocidente. Este sentimento de não pertença a nenhum lugar, um lugar fronteiriço é também uma resposta teórica e política. Ainda que ocupando um não-lugar as mulheres negras demarcaram as sociedades as quais foram integradas inicialmente como mão de obra escrava.

A trajetória destas mulheres está cravada na memória e no cotidiano do imaginário popular com o significado do que de fato traduz o que é viver na resistência. Ademais, a fala da intelectual Lélia Gonzalez, em sua obra “A importância da organização da mulher negra no processo de transformação social" (1988), quando referindo-se a frase de Simone de Beauvoir, explicita perfeitamente bem que:

quando esta afirma que a gente não nasce mulher, mas que a gente se torna (costumo retomar essa linha de pensamento no sentido da questão racial: a gente nasce preta, mulata, parda, marrom, roxinha, etc., mas tornar-se negra é uma conquista). Se a gente não nasce mulher, é porque a gente nasce fêmea, de acordo com a tradição ideológica supracitada: afinal, essa tradição tem muito a ver com os valores ocidentais (GONZALEZ, 1988d, p. 2).

Em “La mujeres puro cuento: la cultura del género" VerenaStolke (2004, p. 93)sugere que é preciso compreender "Como se dá o processo de construção recíproca entre gênero e raça e quais são as condições sócio-políticas que as favorecem?” É dar-se conta que as identidades estão envolvidas por processos dinâmicos sobre estruturas de dominação históricas. A

6 Dados divulgados pelo Comitê da Marcha destacam que as mulheres negras. www.marchadasmulheresnegras.com. Acessado em 3 nov. 2015. 
identidade "Mulher Negra" vista a partir desta ótica não existe em si mesma. Esta é sim, resultado de experiências específicas construídas a partir do legado histórico de tradição africana, que dão sentido às suas demais identidades - gênero, sexualidade e classe, que interseccionadas com raça e etnia - enquanto "elemento estrutural primário" (CRENSAHAW, 1991, p. 1247) — vão influenciar a condução dos mais variados processos organizativos de lutas contemporâneas.

Construídas sob o eixo de opressão, as identidades têm se constituído como demarcador da experiência e ação política de muitas mulheres negras em todos os tempos. É a partir destas que muitas lutas têm sido potencializadas pela garantia dos direitos e acesso às políticas públicas e inclusão social.

\section{Diáspora africana: conceito pertubador para mecânica cultural e histórica do pertencimento}

Questões formuladas até então por/acerca desses persistentes movimentos tomados a partir de seu pertencimento identitário em busca de políticas públicas que reduzam o fosso de desigualdades que separa grupos sociais têm impulsionado intelectuais de diversas matizes, mas sobretudo, negras/os a revisitarem termos, conceitos, métodos, perspectivas e teorias, trazendo para o primeiro plano o diálogo destes com experiências oriundas de culturas vernacular. Essas teorias têm se caracterizado por extrapolar questões ligadas ao colonialismo e a escravidão, focando-se mais e mais nos "estudos das relações raciais" e "diáspora negra". As análises sobre o protagonismo político de sujeitos tão polissêmicos, à luz da noção de diáspora iluminaram limitações políticas, por vezes, evidenciadas nas formas essencialistas e universalistas produzindo "uma perspectiva explicitamente transnacional e intercultural" (GILROY, 2001, p. 57).

A necessidade premente de articular racismo e sexismo às questões cotidianas da vida das mulheres negras a luz da metáfora do "Atlântico Negro" encontra guarida histórica e se apresenta como uma posição política pautada em demandas gritantes em diversos segmentos que necessitam também emergir enquanto políticas públicas e registros para além da memória (GILROY, 2001). Afinal, sujeitos associados às identidades abrigadas por marginalizados têm sido produzidos e incorporados à luta cotidianamente. Mulheres, negras, lésbicas, indígenas, pobres, quilombolas, marisqueiras, trabalhadoras domésticas, vem reivindicando o 
reconhecimento e a efetividade dos chamados novos direitos, muito embora não encontrem guarida para o registro deste protagonismo nos escritos feministas dentre outros tidos como hegemônicos (VALE, 2014, p. 68).

Para obter uma melhor compressão acerca desse tipo de análise é necessário apresentar aspectos elementares do termo diáspora. A origem desta palavra, seguindo a explicação de fornecida por AvtarBrah (2011), é grega. Dia (através de) e speirein(dispersar, propagação). Este supõe uma dispersão a partir de o que expressa uma noção de centro, um lócus, (um lar) de onde se dá a dispersão (2011, p. 212).

Para Ellis Cashmore (2000) o termo apareceu relacionado à traumática experiência de exílio da comunidade judaica dispersa após o chamado "exílio babilônico". Destaca-se aí a forte associação e identificação do termo com a ideia de deslocamento forçado, vitimização, alienação e perda, levando muitos pesquisadores/as a comparar o termo com a experiência vivida pelos povos africanos, asiáticos, armênios, palestinos, irlandeses ou libaneses, dentre outros.

De fato, durante um longo tempo a noção de diáspora esteve presente nas teorias muito mais voltada ao fenômeno do deslocamento geográfico, com fins comerciais, dessas populações. Entretanto, a partir de novas abordagens sobre a dispersão judaica e africana, as narrativas foram sendo reelaboradas por meio de relatos interculturais e anti-etnocêntricos da História. Novos vigores foram acrescentados à esta denominação, de tal modo que, o entendimento que se tem atualmente sobre o termo é que não é qualquer vínculo primordial ou biológico entre as vidas das pessoas na diáspora que promove a aproximação dos sujeitos.

Para Gilroy (2001), no âmbito do Atlântico Negro, não é o corpo negro, em seu sentido físico, absoluto, que aproxima as vidas na diáspora, mas formas similares de tradução dos processos de exclusão e discriminação aos quais está submetido o corpo negro nas sociedades modernas (2001, p. 57).

Já na definição apresentada por Robin Cohen (1997)este termo diáspora tem sido apropriado para descrever a dispersão geográfica de indivíduos pertencentes a uma mesma 'nação', 'grupo étnico' ou 'comunidade' religiosa, em determinadas circunstâncias históricosociais-econômicas-políticas, em suas próprias particularidades. São essas especificidades que fazem com que uma determinada formação diaspórica seja similar ou diferente de outra. Da mesma forma que fazem com que sejam usadas pelos regimes de poder na hora de diferenciar 
um grupo de outro, inclui-los ou exclui-los das construções de "nação", que os inscrevem como sujeitos políticos, jurídicos ou psíquicos.

Isto é em parte porque, como bem salienta Brah (2011), as diásporas contemporâneas não são sinônimas de viagem temporal ocasional, nem tampouco uma metáfora do exílio individual. Ao invés disso, elas surgem das migrações coletivas, viagem dos membros do coletivo como indivíduos, mas, sobretudo, como famílias ou outras combinações. São lugares de comunidade envolvidos na construção de longo prazo, se não permanente, de um "nós" comum, mesmo nos casos em que membros da família se mudam para outro lugar (2011, p. 212).

A ideia trazida por Brah, o fato de que todas as viagens diaspórica são de fato espaços diferenciados, plurais, são constituídos por uma mistura de pessoas heterogêneas, distintas que formam um todo. As trajetórias dos sujeitos envolvidos nestas viagens são, em múltiplas modalidades, vividas e revividas por meio da raça, gênero, classe, religião, língua e geração. Motivo pelo qual, cada diáspora deve ser compreendida na sua especificidade histórica.

Já James Clifford (1997) acredita ser esta palavra um significante, de disputas políticas que definem o local como uma comunidade distinta, em contextos históricos de deslocamento, e não simplesmente de transnacionalidade e movimento (1997, p. 287).

Em sentido abrangente o conceito de diáspora tem contribuído de forma significativa para discutir as teorias da modernidade, alguns objetos e conceitos. No caso, os movimentos sociais negros, ideias como cidadania, desenvolvimento econômico, pertencimento étnico racial e de gênero. $\mathrm{O}$ termo tem instigado para releituras que se proponham a repensar os essencialismo e universalismo, ao priorizar como ponto de partida à história, os contextos, a experiência vivenciada por sujeitos concretos.

\section{Estratégias de enfretamentos na diáspora contemporânea: um caminho sinuoso por outro modelo civilizatório}

As estratégias políticas identificadas no processo de formação e mobilização da Rede de Mulheres Negras traduzem o jeito característico de ser, sentir e viver a vida, aparentemente contraditórias, mas não para provar o poder mobilizador advindo historicamente deste movimento social desde o passado, pois isto já vem sendo realizado por outros autores/as por meio 
de ações concretas o poder coletivo destas mulheres. A força da consciência coletiva de pertencimento étnico-racial e de gênero, para além do espaço/tempo nacional, é importante componente articulador que tem permitido conviver com suas diferenças no interior de seus grupos, com suas tradições, valores, em permanente confronto com a cultura dominante.

Nos primeiros contatos para a pesquisa sobre as organizações que compõem a Rede de Mulheres Negras da Bahia - $\mathrm{RMNB}^{7}$ permitiu a participação em algumas atividades produzidas e observar a forma reincidente com que se remetia à negritude e africanidades, a partir de dados característicos do corpo e valores ancestrais africanos - culturas, religião, tradição, visão de mundo - que eram incorporadas às experiências cotidianas, individual e grupal, como ponto forte de suas atuações.

Embora as organizações que compõem a Rede já desenvolvam ações conjuntas há bastante tempo, vale ressaltar que o início da Rede de Mulheres Negras da Bahia data de 26 de abril de 2014, quando da sua fundação, na sede da organização, Projeto Bahia Strett ${ }^{8}$. Essa é apenas a etapa mais recente do ativismo político das organizações que agregam sua estrutura, pois elas têm um histórico e perfil político caracterizado pela resistência ao racismo, sexismo e lesbofobia. Assim definiram na sua $1^{\circ}$ Reunião de Formação da Rede que estas organizações deliberariam sobre a sua composição:

\begin{abstract}
"organizações com perfil político caracterizado pela resistência ao racismo, sexismo e lesbofobia; consolidação de novos sujeitos políticos e movimentos sociais; lutam contra todas as formas de discriminação, desigualdades sociais, econômicas, políticas e civis; a universalização e construção de novos direitos e a consolidação de espaços democráticos de poder; pela construção de modos sustentáveis de vida e pela radicalização da democracia, do pluralismo e do bem viver". ${ }^{9}$
\end{abstract}

Este movimento que visa atuar no território nacional em defesa dos interesses deste segmento, pela construção de modos sustentáveis de vida, tem na radicalização da democracia, do pluralismo e do bem viver o principal motivo da sua existência. Conforme prescreveram, esta organização insurge contra os modelos de desenvolvimento econômico e político

7 Odara, MNU, Bahia Strett, Flor de Lotus, Sou Digna, Afoxé Cabalaguanze, Instituto Yalodê, AMULETO, Coletivo de Mulheres do Calafate, Casa de Mulheres, Iceafro, Ama Cruz das Almas, Instituto Búzios, Mulheres da Vasco da Gama e tantas outras.

Projeto Bahia Street, localizado no bairro do Dois de julho, Centro de Salvador, atua no empoderamento meninas em situação de vulnerabilidade social, através do conhecimento, facilitando a sua ascensão socioeconômica, política e cultural. http://correionago.com.br/portal/bahia-street-completara-20-anosemponderando-meninas-atraves-da-educacao/. Acessado em 28 dez. 2015.

9 Relatório do I Encontro do Movimento de Mulheres Negras para Fundação da Rede de Mulheres Negras da Bahia. Data de Fundação: 26 de abril de 2014, na cidade de Salvador (BA). 
desigual, adotado pelo Estado, contra o qual serão levantadas as bandeiras reivindicativas de inclusão de parcela significativa da população brasileira. Destaque-se, ainda, a necessidade de construção do legado histórico deixado por aquelas que um dia ousaram denunciar as práticas e força ideológica do racismo e do sexismo combinados que se perpetuam nesta sociedade.

Considerando sua origem e o contexto histórico no qual se insere, a RMNB em busca de uma nova cultura política diz ainda em seu documento de fundação, que defende e se propõe a vivenciar a partir das organizações que a representam, os seguintes valores: Identidade, ancestralidade e religiosidade; Tradição cultural negra; Experiência; Legado histórico de luta; Autoestima e combate aos estereótipos; Política sexual. ${ }^{10}$

Além da defesa dos seguintes princípios: Autonomia e independência - A RMNB é independente de qualquer grupo político, religioso, empresarial ou governamental. Não aceita contribuições que impliquem posicionamento predeterminado diante de qualquer tema ou outro procedimento que de alguma forma comprometa a integridade intelectual de seus trabalhos e sua missão; Apartidária - É uma organização que não apoia candidatos ou partidos políticos. Seu compromisso é com o fluxo livre de informação e com o debate transparente e aberto que mantenha seu foco em propostas de soluções concretas para o avanço e o empoderamento de mulheres negras, enquanto sujeito coletivo e político, e não em pessoas ou ideologias ${ }^{11}$.

Extrapolando territorialidades, por meio de uma metodologia própria para suas estratégias políticas, a RMNB realizou inúmeros eventos (caravanas, encontros, seminários) estimulando a observação de como esse coletivo diversificou a forma de organização, não apenas no que concerne à estrutura, mas, sobretudo, na ação política adotada no processo de articulação da I Marcha de Mulheres Negras à Brasília.

Podemos destacar, ainda que de forma sucinta, algumas dessas ações que objetivaram publicizar as bandeiras de luta das mulheres negras no estado da Bahia contra a violência e pelo bem viver:

- A Marcha das Mulheres Negras cria corpo na III CONAPIR - Conferência de Promoção da Igualdade Racial, quando é tirada a Confederação Executiva Nacio-

10 Relatório do I Encontro do Movimento de Mulheres Negras para Fundação da Rede de Mulheres Negras da Bahia. Data de Fundação: 26 de abril de 2014, na cidade de Salvador (BA).

11 Relatório do I Encontro do Movimento de Mulheres Negras para Fundação da Rede de Mulheres Negras da Bahia. Data de Fundação: 26 de abril de 2014, na cidade de Salvador/BA. 
nal da Marcha, ou Comitê Impulsor Nacional com o papel de organizar em todo território nacional o ato.

- As caravanas da RMNB pelo estado da Bahia com o objetivo de planejar a implementação da Rede, formar e mobilizar as mulheres para a I Marcha levou o debate sobre o radicalismo contra o racismo, a todas as formas de violência e pelo bem viver a diversos destinos, a exemplo de Cachoeira do Paraguaçu, Cruz das Almas, Camaçari, São Francisco do Conde, Feira de Santana e Serrinha. Teve início em Cachoeira, maio de 2014 e suspensas em abril de 2015, em Feira. Fazendo um resgate do que foram as articulações da RMNB a partir desses encontros, Valdecir Nascimento relata o seguinte:

Em maio de 2014 fizemos nosso lançamento em Salvador e saímos em caravana inicialmente em direção ao Recôncavo para beber as águas de Cachoeira, pedimos licença as ancestrais na pessoa de Dona Dalva da Casa do Samba. Subimos até Cruz das Almas, tomamos banho de mar de Arembepe e dançamos o Samba de Roda em São Francisco do Conde. Agora estamos encerrando nossas atividades de 2014 aqui em Serrinha. O fato é que nós somos o estado do Brasil que mais se desenvolveu no que diz respeito à Rede e mobilização para a marcha ${ }^{12}$.

A ideia da Marcha veio à tona pela primeira vez, por ocasião do Encontro Paralelo da Sociedade Civil para o Afro XXI: Encontro Ibero-Americano do Ano dos Afrodescendentes, realizado no TulipInn Hotel, Salvador-BA (16 a 20 de novembro de 2011). ${ }^{13}$ Esta proposta de se construir uma marcha, mobilizando as pessoas a partir de especificidades expressas em uma tradição e identidade étnica de matriz africana foi realizada, em primeira mão, por Nilma Bentes, uma das fundadoras do Centro de Estudos e Defesa do Negro do Pará. Inicialmente esta marcha foi pensada para acontecer em 13 de maio de 2015, considerado o Dia Nacional de Denúncia Contra o Racismo.

Entretanto, em reunião nacional realizada nos dias 06, 07 e 08 de dezembro de 2014, pela Articulação de Mulheres Negras Brasileiras - AMNB, em Brasília, foi cogitada a possibilidade de mudança da data da Marcha. O que causou muito espanto para as representantes da Bahia considerando o fato de que nesta ocasião a Marcha já estava na rua. Por conta disso a-

12 Fala de Valdecir Nascimento, extraída doRelatório da Caravana de Serrinha, realizada nos dias 15 e 16 de novembro de 2014, na Escola Maria Aurea, Cidade Nova - no município de Serrinha (BA).

13 Até então as mulheres Negras haviam realizado três atos políticos a nível nacional. O I e II Encontros Nacionais de Mulheres Negras, sendo o primeiro na cidade de Valença (RJ) (1988) e o segundo na cidade de Salvador (BA) (1991). 
valiaram durante a Caravana de Feira de Santana ser esta medida um forte fator de desmobilização, conforme o relato de Naiara Leite que esteve presente nesta reunião:

\begin{abstract}
Nessa ocasião, saímos da reunião sem nenhuma posição definida em relação a tal mudança, mas fizemos questão de deixar evidente que tínhamos interesse na discussão sobre a modificação desta data. Fizemos uma série de considerações sobre o prejuízo desta mudança.O fato é que mais adiante fomos surpreendidas mudança já postada na rede sem um diálogo do este desfecho. Esta atitude nos fez recuar internamente para avaliar o significado deste processo e sua repercussão na conjuntura local e regional. Porque a Rede não é somente Brasília, São Paulo e Rio. ${ }^{14}$
\end{abstract}

Vale ressaltar que episódio semelhante já havia ocorrido no I Congresso Internacional sobre o Pensamento das Mulheres Negras, entre 09 a 12 /12/2014, em Salvador. Durante este evento, em reunião foi convocada para discutir questões relativas ao processo de organização da Marcha foi proposta inicialmente por algumas organizações do sudeste a mudança de data. Isso resultou em um forte embate devido ao fato da Bahia discordar da mudança de data para 18 de novembro. - Isto é loucura! Zumbi vai engolir Dandara. Diziam as mulheres insatisfeitas. Diante de tantos desencontros a Bahia juntamente com alguns estados do Nordeste e Minas Gerais decidiram por manter uma Marcha local no dia 13 de maio, realizando na data programada um Ato - Marcha até a Governadoria do Estado, no CAB.

A Marcha se preocupou em apresentar uma proposta alternativa para o progresso da humanidade, baseada em saberes da tradição africana articulada a uma forma de ser e estar neste não-lugar, de fronteira, que tem possibilitado a essas mulheres uma visão privilegiada dos fenômenos sociais que atinge em cheio suas vidas impedindo-as de uma realização plena enquanto cidadãs.

\title{
Considerações finais
}

Ainda que de forma panorâmica, o processo de construção e organização da Rede de Mulheres Negras em torno da luta antirracista e antissexista, entre os anos de 2013 a 2015 apontam para o trabalho de articulação política das mulheres negras para a I Marcha de Mulheres Negras à Brasília (2015).

14 Fala de Naira Leite, extraída doRelatório da Caravana de Feira de Santana, realizada em 11 de abril de 2015, nomunicípio de Feira de Santana (BA). 
As estratégias de mobilização utilizaram-se de termos como identidade étnica e diáspora africana que influenciam diretamente sobre suas experiências e ação política cotidiana, mais que isso, explicitou a multiplicidade de visões que perpassam a pluralidade dessas mulheres, que a partir desse lugar de fronteira, têm possibilitado uma visão privilegiada dos fenômenos sociais, em especial, a dinâmica dos processos de exploração instituído por um modelo de desenvolvimento liberal de supremacia branca e patriarcal.

A organização da Rede de Mulheres Negras, juntamente com a articulação da I Marcha à Brasília, tem servido para expor múltiplas visões, constatar que, além dessas questões relacionadas ao fenômeno do racismo e sexismo combinados, há também outras formas de opressões. Esta sabedoria milenar, inspirada na experiência e ancestralidade africana tem sido o mote da sua ação e prática política contrária à cristalização de lugares sociais para as pessoas negras na sociedade, cidadania e garantia de uma vida sem racismo.

A recente trajetória da Rede de Mulheres Negras pode nos sugerir a seguinte questão: em que medida esse movimento pode ser considerado uma manifestação de valores africanos que se opõe ao modelo civilizatório dominante de supremacia eurocêntrica? A resposta seria negativa para os que adotam como referência conceitos pautados por pressupostos modernos, que ignoram a diversidade e complexidade dos processos forjados na diáspora e reduz sua compreensão a regras estabelecidas independentemente das circunstâncias e contextos históricas que os motivaram.

Ademais, quando um movimento é analisado a partir da multiplicidade de intenções, instrumentos e estratégias de constituição de um espaço autônomo, dentro do processo de resistência aos sistemas de opressão e exploraçãoa revelia dos contextos e circunstâncias históricas, essas definições estáticas perdem a validade como ferramenta analítica. Por isso, não há como não reconhecer a Rede como uma estratégia de luta antirracista e antissexista, que enquanto organização feministas negras inspirada por valores característicos da sua condição de diáspora - identidade, ancestralidade, religiosidade e tradição cultural africana, vem dinamizando a luta das mulheres negras no Brasil.

\section{Referências}

BRAH, Avtar. Cartografia de la diáspora: identidades encuestión. Madrid: Traficantes de Sueños, 2011, p. 212. 
CASHMORE, Ellis. Dicionário de relações étnicas e raciais. São Paulo: Selo Negro Edições, 2000.

COLLINS, P. H. Rasgos distintivos delpensamiento feminista negro. In: Jabardo, Mercedes (Org.). Feminismos Negros: una antologia. Madrid, Traficante de Suenos, 2012, p. 104.

COHEN Robin. Global Diasporas: An Introduction. Seattle: University of Washington Press, 1997.

COHEN, Robin. Sólidas, dúcteis e liquidas: noções em mutação de "lar" e "terra natal nos estudos da diáspora. Cadermo CRH, v. 21, n. 54, Salvador, 2008.

CLIFFORD, James (1997). Diasporas. In: Montserrat Guibernau and John Rex (Ed.) The Ethnicity Reader: Nationalism, Multiculturalism and Migration, Polity Press, Oxford. p. 287.

DURAND, Gilbert (1999). O imaginário. Difel, São Paulo.

GILROY, Paul. O Atlântico Negro: Modernidade e dupla consciência. São Paulo: Editora 34; Rio de Janeiro: UCAM, Centro de Estudos Afro-Asiáticos, 2001, p. 256.

HALL, Stuart. Da diáspora: identidades e mediações culturais. Belo Horizonte/Brasília: UFMG/UNESCO, 2003. COHEN, Robin. Sólidas, Dúcteis e Líquidas: noções em mutação de "lar" e "terra natal" nos estudos da diáspora. Caderno CRH, Salvador, v. 21, n. 54, p. 519-532, Set./Dez. 2008.

LATOUCHE, Serge. Pode a África contribuir para resolver a crise do Ocidente? IV Congresso Internacional de Estudos Africanos, Barcelona 12-15 de janeiro de 2004. Trad. Acácio Sidinei Almeida Santos 2013, p.195.

SILVA, Joselina. I Encontro Nacional de Mulheres Negras: o pensamento das feministas negras na década de 1980. In: SILVA, Joselina; PEREIRA, Amauri Mendes. O Movimento de Mulheres Negras: escritos sobre os sentidos de democracia e justiça social no Brasil. Belo Horizonte: Nandyala, 2014. p. 13-40.

SPIVAK, GayatriChakravorty. Death of a discipline. New York: Columbia University Press, 2003.

STOLKE, Verena. La mujeres puro cuento: la cultura del género. Revista Estudos Feministas. Vol.12. n.2. Rio de Janeiro. 2004.

VALE M.M. Mulheres Negras na Política: Trajetória social e política de mulheres negras candidatas às eleições municipais de Salvador (2008 -

2012).https://repositorio.ufba.br/ri/bitstream/ri/18291/1/Disserta\%C3\%A7\%C3\%A3o\%20de $\% 20 \mathrm{Ma} \% \mathrm{C3} \%$ ADsa\%20Maria\%20Vale.pdf. 2014, p. 68. Acessado em 18/12/2015.

Recebido em 2 de agosto de 2015.

Aceito em 23 de setembro de 2015. 
